(16 $\mathrm{mg}$ in $0.5 \mathrm{ml}$ of solution for pepsin). In addition, even though the spectra are markedly simplified by this technique, spectral overlap may still be a problem if multiple labels are employed. In these cases, however, it may be possible to resolve the overlapping peaks by editing 2-dimensional NMR spectra in a third dimension using the heteronuclear frequencies in a three-dimensional NMR experiment ${ }^{14}$.

The potential applications of these techniques are vast. In one application, the structural information that can be obtained from enzyme/inhibitor complexes through isotope-editing may aid in the design of nonpeptide enzyme inhibitors, eliminating the poor absorption and proteolytic instability inherent in peptide inhibitors. The ability to measure $\mathrm{NH}$ exchange rates will help to improve the inhibitor by identifying the amides of the inhibitor that are not involved in binding to the enzyme, and that can be removed or altered. Information on the conformation of enzyme-bound inhibitors can be used to suggest new analogues which contain metabolically stable structural frameworks designed to orient spatially the functional groups of the inhibitor for maximum interaction with the enzyme. Finally, knowledge of the structure of the active site will suggest ways to modify inhibitors to fit better into the active site, or ways to change undesirable physical properties of the inhibitor (such as where to attach hydrophilic groups to improve water solubility) without altering the binding affinity of the inhibitor. Indeed, the structural information that can be obtained on the interactions of labelled inhibitors with enzymes or soluble receptors from isotope-editing techniques should be very useful in the design of therapeutic useful pharmaceutical agents.

Stephen $W$. Fesik is at the Pharmaceutical Discovery Division, Abbott Laboratories, Abbott Park, Illinois 60064, USA. For more information, fill in reader service number 100.

1. Wuthrich, K. NMR of Proteins and Nucleic Acids (Wiley, New York, 1986).

2. Freeman, R.. Mareci, T.H. \& Morris. G.A. J. magn Reson. 42, 341-345(1981).

3. Bendall, M.R., Pegg, D.T. Doddrell, D.M. \& Field, J. J. Am. chem. Soc. 103,934-936 (1981).

4. Griffey, R.H. \& Redfield, A.G.J. magn. Reson. 65.344 347 (1985).

Griffey, R.H. Jarema, M.A., Kunz, S., Rosevear, P.R. \& Redfield. A.G. J. Am. chem. Soc. 107, 711-712 (1985).

6. Wilde, J.A., Bolton. P.H., Stolowich, N.J. \& Gerlt, J.A J. magn. Reson. 68, 168-171 (1986).

7. Otting, G., Senn, H., Wagner, G. \& Wuthrich, K. J. magn. Reson. 70. 500-505 (1986).

8. Rance, M., Wright, P.E.. Messerle, B.A., \& Field, L.D. J Am. chem. Soc. 109,1591-1593 (1987)

9. Bax. A. \& Weiss, M.A. J. magn. Reson. 71, 571-575 (1987)

10. Fesik, S.W., Gampe, R.T., Jr., \& Rockway, T.W. J. magn. Reson. 74, 366-371 (1987).

11. Fesik, S.W., Luly, J.R., Stein, H.H., \& BaMaung, N Biochem. biophys. Res. Commun. 147. 892-898 (1987).

12. Fesik, S.W. et al. in Proceedings of the 10th American Peptide Symposium (ed. Marshali, G. R.) 57-59 (ESCOM, Leiden, 1988).

13. Fesik, S.W., Luly, J.R., Erickson, J.W. \& AbadZapatero, C. Science, submitted.

14. Fesik, S.W. \& Zuiderweg, E.R.P. J. magn. Reson., (in the press)

\section{FASEB in Las Vegas}

Next week, over 16,000 scientists will travel to Las Vegas, Nevada for the annual meetings of the Federation of American Societies for Experimental Biology and the American Society for Biological Chemistry and Molecular Biology. Selections from the more than 450 companies with exhibit booths are described below.

In booths 411 and 413 , Sanki Laboratories will be introducing its preparative/analytic centrifugal partition chromatography system, the model LLN-5 (Reader Service No. 101). Centrifugal partition chromatography $(\mathrm{CPC})$ is a liquid-liquid chromatographic technique which utilizes liquid-liquid partition and countercurrent distribution to fractionate complex mixtures of chemical substances. Because no solid support matrix is used in CPC, irreversible retention of highly retentive

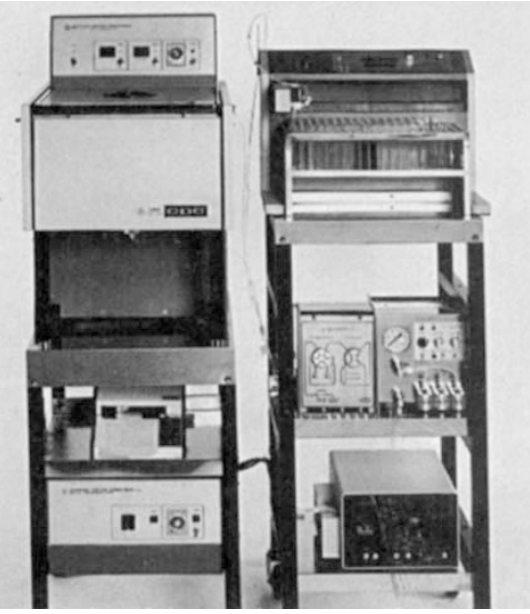

Sanki's centrifugal partition chromatograph.

sample components is eliminated. The stationary phase is retained in the column by centrifugal force, so high mobile phase flow rates may be used without appreciable loss of resolution. Sanki says the $\$ 25,000$ 55,000 (US) model LLN-5 CPC system can be used to separate and purify a broad range of synthetic and naturally occurring chemical species, and offers particular advantages in the isolation of polar substances.

Cambridge Technology, Inc. will be showing off its new model 2600 series scintillation cocktail distribution pumps in booth 1435 (Reader Service No. 102). The pumps permit up to 24 vials to be filled with $6 \mathrm{ml}$ of any kind of liquid scintillation counter cocktail in approximately 2 seconds, says the company. The semiautomatic system can distribute cocktail from any size or shape of container. The units tie into a central vacuum system or small laboratory vacuum pump, and are operated using a foot pedal. Distribution heads are available for most major models of liquid scintillation counters and

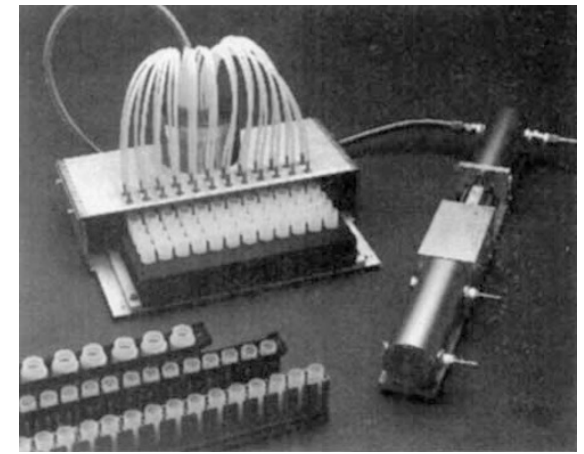

A pump for filling scintillation cocktail vials.

Cambridge Technology's cell harvester vial trays. The $\$ 1,850$ (US) price of the pumps includes a choice of distribution heads and foot pedals.

All available synthesis chemistries can be used with the Microsyn 510 DNA synthesizer from Perkin-Elmer Cetus, on exhibit in booths 738-841 (Reader Service No. 103). Using the beta-cyanoethyl phosphoramidite chemistry, the company says the fully automatic Microsyn 510 produces oligonucleotides at coupling yields of 98.5 per cent per step or better, with minimal depurination. The synthesizer has a patented syringe delivery system which ensures the production of reproducible DNA sequences, and which provides proportional delivery of phosphoramidite bases for the preparation of mixed probes. The $\$ 23,500$ (US) Microsyn 510 also has a built-in safety feature to prevent exposure of the user to pressur-

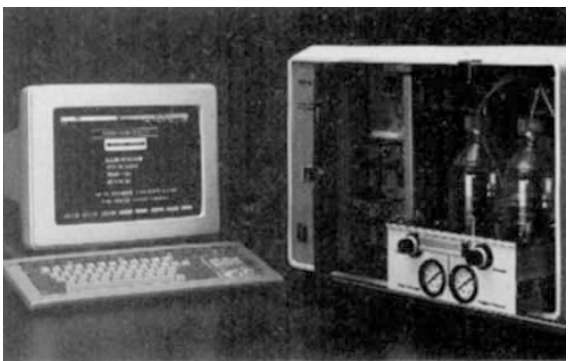

A DNA synthesizer that uses all chemistries.

ized reagent bottles, and a self-monitoring signals system failures, low gas levels or empty reagent bottles.

For detecting viral infections in laboratory mice and rats, Organon Teknika offers a range of animal diagnostic test kits system which automatically detects and 
(Reader Service No. 104). The tests are based on the principles of solid phase ELISA and require no special reading equipment. Viral antigen, attached to ferrous metal beads, captures specific antibody if present in the test serum. The beads are then incubated with peroxidase conjugated anti-mouse antibodies, and a final incubation with substrate yields a green colour in positive specimens. Among the range of viruses that may be detected are Sendai virus, hepatitis (MHV), pneumonia (PVM), reovirus type 3 and rat coronavirus (RCV/SDA), Each $£ 415$ (UK) kit provides 94 determinations; combined test kits which detect four different viruses are also available. Organon Teknika will be exhibiting in booth 261 .

Dagan Corporation, in booth 1454 , has a new integrating patch clamp in which the headstage resistor has been replaced with

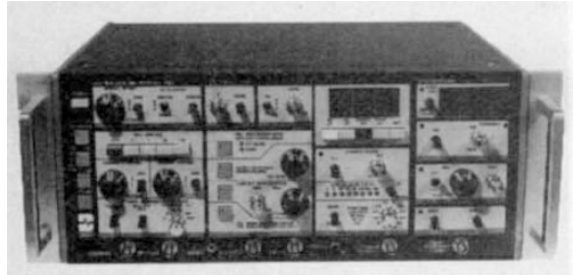

Integrating patch clamp from Dagan.

a capacitor (Reader Service No. 105). Dagan says this design provides 1,000 times better frequency response and substantial noise reduction, and that additional benefits include the absorption of very large current spikes and the simplification of series resistance and capacity compensation controls. The model 3900 patch clamp can be interfaced with any computer because all modes, modifiers, gain, and auto search can be controlled remotely. An optional module specifically for planar lipid bilayers expands the capacity compensation range, delivers a triangle wave and has a fast charge system to charge the bilayer. Dagan's integrating patch clamp costs $\$ 4,900$ (US).

\section{Sampling and analysis}

The use of intact undegraded mRNA is of primary importance to the success of any

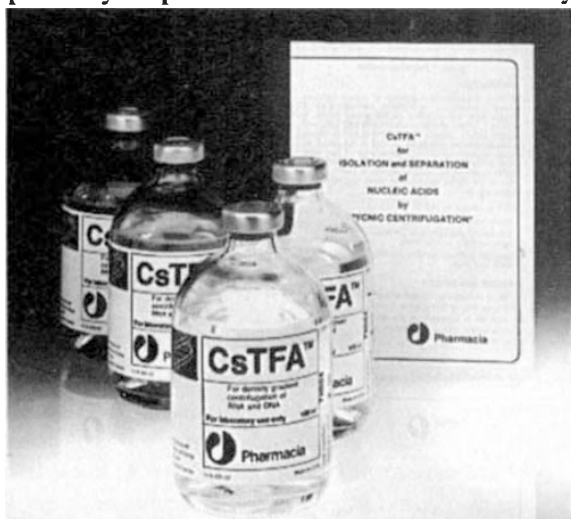

Pharmacia's solution for isolating RNA.
cDNA library construction. For the preparation of high yields of intact polyadenylated mRNA, Pharmacia LKB, exhibiting in booths from 1116 to 1421 , offers cesium trifluoroacetate solution (CsTFA) for use in the centrifugation step in the guanidinium thiocyanate/CsTFA procedure of Okayama-Berg (Reader Service No. 106). Pharmacia LKB says DNA fragments, which could interfere with cDNA cloning, are removed completely. CsTFA solution solubilizes and dissociates proteins from nucleic acids without the need for detergents, and is crucial to applications where reduction of unpleasant phenol extraction or lengthy proteinase digestions is the objective. It is also useful for the isolation of both single and double-stranded RNA and DNA from cells, viruses and organelles.

ChromStation $/ 2$ is the newest chromatography workstation from SpectraPhysics (Reader Service No. 107). The $\$ 6,900$ (US) ChromStation/2 couples a multichannel data system with a LC system controller. Designed for the IBM PS/2 series of computers, the workstation performs tasks from collecting and storing data to reintegrating and writing up the results in a spreadsheet. With ChromStation $/ 2$, the chromatographer is able to operate several programs simultaneously

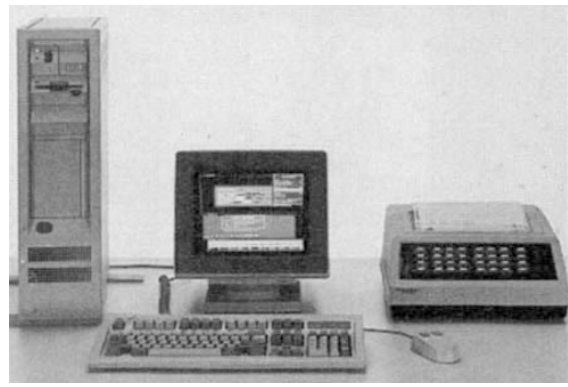

Chromatography with the IBM PS/2 from Spectra-Physics.

using a multitasking operating environment; switching between programs is accomplished with a click of the mouse. Equipped with a Spectra-Physics Labnet communications interface, the ChromStation/2 can collect data automatically from up to eight channels, store it on disk, and transfer it to other chromatography software programs. Spectra-Physics will be showing its full line of chromatography systems, including the ChromStation $/ 2$, in booths 111 and 113 .

The Ultrafree-MC filter unit and personal centrifuge from Millipore are intended for sample preparation of microlitre volumes of solution prior to HPLC and ion chromatography analysis (Reader Service No. 108). The Ultra-free-MC filter unit is designed for the removal of cells and particulates, and for the purification and recovery of proteins, enzymes and virus. It is available with both ultrafiltration and low-binding microporous membranes, and the unit's standard $1.5 \mathrm{ml}$ conical tube also fits conventional centrifuges. The $\$ 350$ (US) Millipore personal centrifuge is smaller than a standard stir plate, and can be operated in a laminar flow hood, a refrigerator, or other crowded areas. There are no timers to set and or switches to operate. Millipore is exhibiting in booths 186-287.

\section{The gel lane}

Molecular Dynamics will be unveiling a new development in densitometry in booth 275 (Reader Service No. 109). The company's model 300A Computing Den sitometer 'reads' a gel or an autoradiograph in the same way that an optical scanner reads a printed page. The densitometer uses a line scanner and an integrating cylinder to analyse the entire gel area at once, not just individual lanes. The sample moves in one direction, while the the light beam moves in a perpendicular direction, so the densitometer scans every data point. Molecular Dynamics says the model $300 \mathrm{~A}$ can analyse a $36 \mathrm{~cm} \times 43 \mathrm{~cm}$ gel in just three minutes, and that the light integrating cylinder collects virtually all of

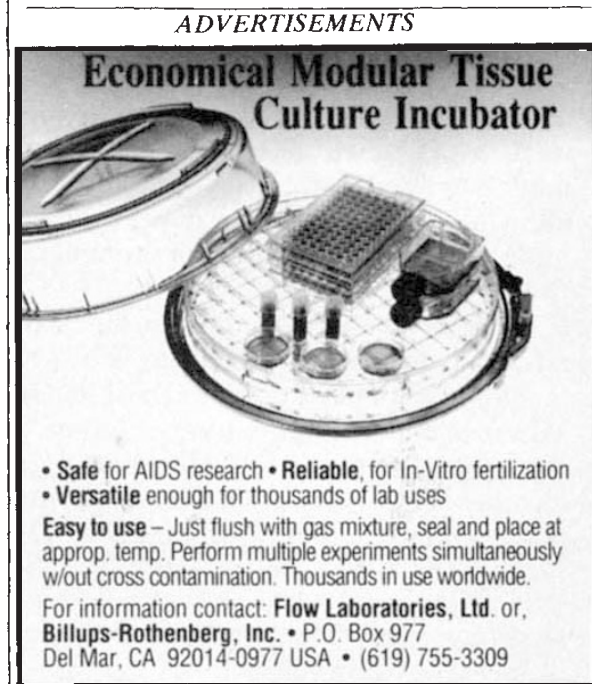

Reader Service No.25

\section{Ged SINGER}

MICROINJECTION?

- SINGER MKI

- SINGER MKIII

- SINGER MICROFORGE

SINGER INSTRUMENT CO LTD TREBOROUGH LODGE

ROADWATER, WATCHET SOMERSET TA23 OQL

Tel: 0984-40226

Telex: 337492 COMCABG

Reader Service No.50 


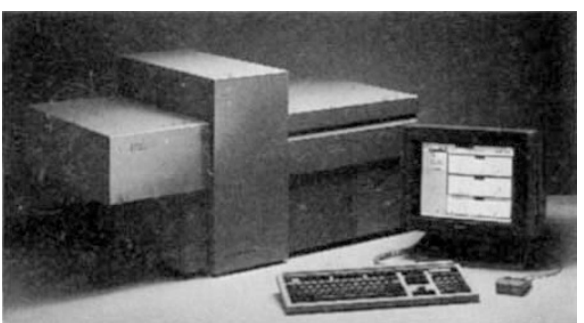

A new slant on densitometry.

the transmitted light so accurate measurements can be made even in the 3 to 4 optical density range. The system's computer uses Windows-based software, allowing the results from up to four gels to be viewed simultaneously for comparison. Molecular Dynamics sells the model 300A Computing Densitometer for $\$ 29,500$ (US).

Bio-Rad will have selections from its product range on display in booths $1043-$ 1050. New from Bio-Rad are sequencing wedge spacers for its $40-$ and $50-\mathrm{cm}$ long Sequi-Gen DNA sequencing cells (Reader Service No. 110). Wedge spacers produce more closely spaced bands at the bottom of the gel, increasing the number of readable bases per lane. The $40-\mathrm{cm}$ long spacers form gels 0.25 to $0.53 \mathrm{~mm}$ thick, and the $50-\mathrm{cm}$ long spacers form gels 0.25 to $0.75 \mathrm{~mm}$ thick. Wedge spacers eliminate the need for buffer gradient gels, allowing the use of standard polyacrylamide solutions and buffers for sequencing.

Bethesda Research Laboratories, exhibiting in booths from 1656 to 1757 , has recently announced the launch of its GelMix 6 pre-mixed gel-casting solution for the preparation of sequencing gels (Reader Service No. 111). The six per cent polyacrylamide solution includes TBE buffer, urea and TEMED, and BRL says it remains stable for six months. Preparation of gels using the solution is easy: researchers just add ammonium persulpate to the bottle, mix it for 30 seconds, and pour the solution into the gel mould. The Gel-Mix 6 comes in packages of six 75 -ml bottles; each bottle makes a standard sized $33 \mathrm{~cm} \times 40 \mathrm{~cm} \times 0.04 \mathrm{~cm}$ gel.

The Kodak company named Bio Image will be displaying its range of machine vision image analysis instruments for gel electrophoresis in booths 1244 and 1343 . Bio Image offers a benchtop analyser the

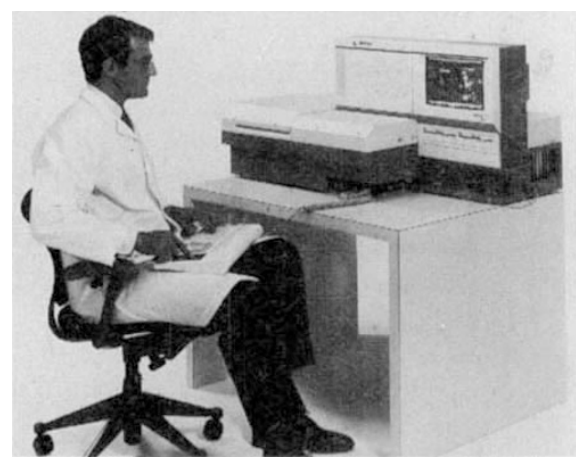

Benchtop gel analysis from Bio Image.

size of a densitometer, the Visage BT (Reader Service No. 112). The Visage BT acquires images by transmittance or reflectance using a $512 \times 1$ solid state photodiode array. The system offers selectable $50 \mu$ per pixel or $100 \mu$ per pixel resolution. The CPU of the system is an Intel 80286 16-bit microprocessor which supports MS-DOS, and images are displayed on a 12-inch high resolution monitor. The analytical capabilities of the Visage BT include 1- dimensional electrophoresis quantification and 2-dimensional spot quantification.

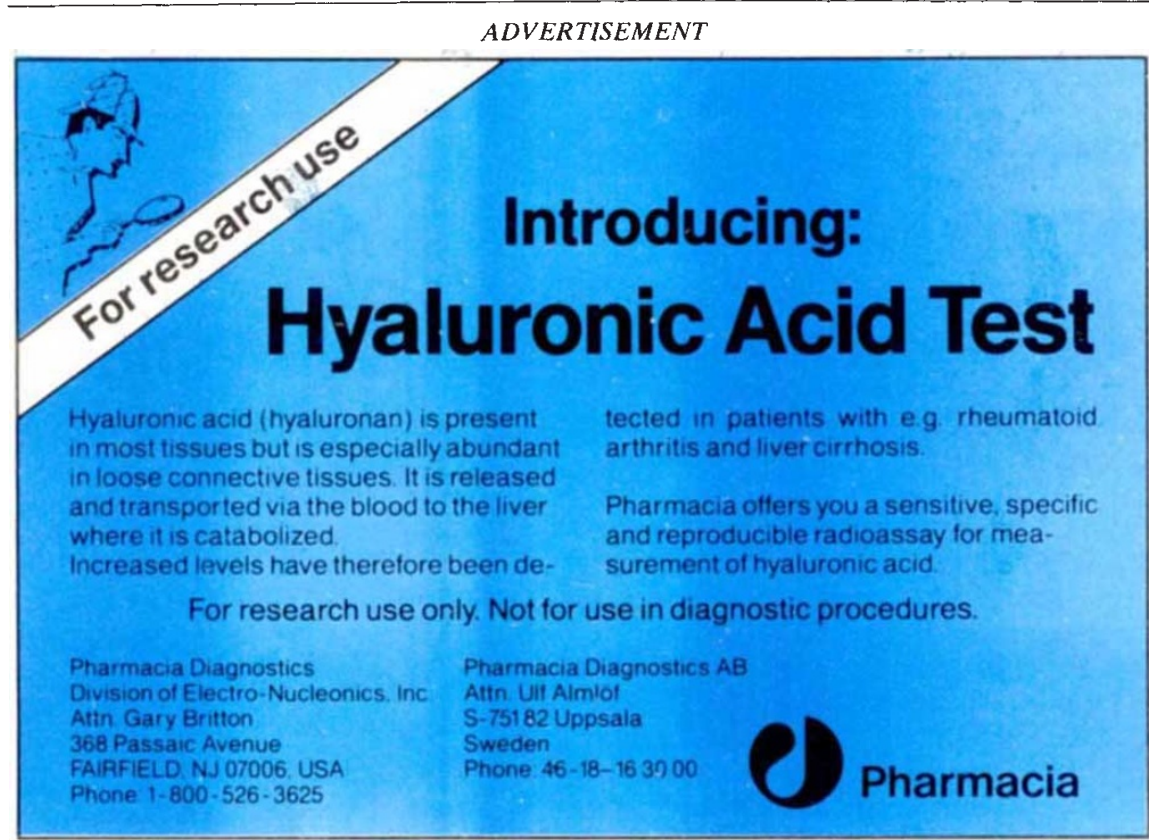

Reader Service No.49

\section{Reagents and kits}

Two new products for the use and handling of chromogens for peroxidase and pseudo-peroxidase reactions are available from ICN Biomedicals, Inc., exhibiting in booths 1124-1132 (Reader Service No. 113). ICN Biomedicals offers both a soluble chromogen solution, TMB, for ELISA and an insoluble chromogen solution, 4-chloro-1-naphthol, for immunohistology procedures. The two substrates are available in ready-to-use solution form, eliminating the need to make up new chromogens for each enzyme reaction. The chromogens are combined with peroxide and stabilizers so that they can be used directly as the final step in developing the colour indicator in the enzyme reaction. ICN Biomedicals sells the chromogen/substrate solutions for $\$ 110$ (US) for $50 \mathrm{ml}$.

Molecular Biology Resources, in booth 1666 , will be introducing its immunoaffinity purified human DNA polymerase $\alpha$-primase (Reader Service No. 114). DNA polymerase- $\alpha$ is a key component in the chromosomal replicating apparatus of higher eukaryotes, and MBR's DNA polymerase- $\alpha$ should be useful in studies requiring reconstitution of model eukaryotic DNA replicating systems. The polymerase is analysed for contaminating exoand endonucleases, and is functionally tested in a DNA polymerase $\alpha$-primasedependent M13 replication system. MBR sells the DNA polymerase $\alpha$-primase in 50 and 200 unit packages, for $\$ 84$ and $\$ 310$ (US), respectively.

\section{Software}

Recombinant Toolkit is the name of the newest software package from Biosoft, exhibiting in booth 1579 (Reader Service No. 115). Recombinant Toolkit is a DNA and amino acid sequence analysis package compatible with IBM PCs equipped with a colour monitor. The $\$ 350$ (US) software finds restriction sites for approximately 100 restriction enzymes, performs sequence searches and translates DNA sequences to peptide/protein sequences. Special functions include: codon counts for checking the validity and nature of active sequences, start/stop/renumbering facilities for defining a subsequence of an active sequence or for renumbering sequences, and the ability to modify tables of restriction enzymes or genetic codes. The hydropathy feature illustrates protein sequences of up to 700 amino acids using colour gradients to indicate the moving average or hydrophobic moment.

These notes are compiled by Carol Ezzell from information provided by the manufacturers. To obtain further details about these products, use the reader service card bound inside the journal. Prices quoted are sometimes nominal and apply only within the country indicated. 